\title{
BMJ Open Birthweight features of the infants of mothers diagnosed with diabetes at different gestational ages in South China from 2014 to 2018: a retrospective study
}

\author{
Xin-xin Huang (D) , ${ }^{1}$ Xiu-Min Jiang, ${ }^{2}$ Qing-Xiang Zheng, ${ }^{2}$ Xiao-Qing Chen, ${ }^{2}$ \\ Yu-Qing Pan $^{3}$
}

To cite: Huang $X$, Jiang $X-M$, Zheng Q-X, et al. Birthweight features of the infants of mothers diagnosed with diabetes at different gestational ages in South China from 2014 to 2018: a retrospective study. BMJ Open 2021;11:e042476. doi:10.1136/ bmjopen-2020-042476

- Prepublication history for this paper is available online. To view these files, please visit the journal online (http://dx.doi. org/10.1136/bmjopen-2020042476).

Received 07 July 2020

Revised 03 February 2021

Accepted 22 February 2021

\section{Check for updates}

(C) Author(s) (or their employer(s)) 2021. Re-use permitted under CC BY-NC. No commercial re-use. See rights and permissions. Published by BMJ.

${ }^{1}$ Healthcare, Fujian Maternity and Child Health Hospital, Affiliated Hospital of Fujian Medical University, Fuzhou, China

${ }^{2}$ Nursing Department, Fujian Maternity and Child Health Hospital, Affiliated Hospital of Fujian Medical University, Fuzhou, China

${ }^{3}$ College of Nursing, Fujian Medical University, Fuzhou, China

Correspondence to Dr Xiu-Min Jiang; jxm550@163.com

\section{ABSTRACT}

Objectives The primary purpose was to measure the birth weight of infants of mothers with gestational diabetes (IMGDs) at different gestational ages to develop new reference charts and curves for them. A further purpose was to compare them with those of 159334 infants in China to provide more accurate reference charts for the diagnosis of suspected abnormal birth weight of IMGDs. The final purpose was to evaluate the key periods for such mothers to control their weight in line with the difference of fetal weight of each two neighbouring gestational ages. Setting A specialised hospital in South China Participants IMGDs born here from January 2014 to December 2018.

Primary and secondary outcome variables Birth weight, gestational ages of IMGDs, gender and year of birth.

Results Data of 14311 singleton live births at the gestational weeks 25-42 here were collected. The proportions of low birth weight, normal birth weight and macrosomia were $7.26 \%, 87.04 \%$, and $5.70 \%$, respectively. The proportions of small for gestational age, appropriate for gestational age and large for gestational age were $5.69 \%, 84.42 \%$ and $9.89 \%$, respectively. In the macrosomia group, the mean of all birth weight in 2017 decreased for the first time since 2014. Both the means of birth weight of male infants at gestational weeks 36-41 and of female at weeks 38-40 were greater than that of the 159334 infants. The increase of each weekly mean of IMGDs at gestational weeks 27-31 and 33-35 was $>10 \%$ compared with the former. Based on this, new reference charts of birth weight for IMGDs in terms of different gestational age and gender were formulated.

Conclusion These charts may be applied as reference for more accurate diagnosis and quick treatment of abnormal birth weight. This study showed that the identification of key periods for fetal weight gain was helpful for the management of the weight of women with gestational diabetes.

\section{INTRODUCTION}

Gestational diabetes mellitus (GDM) is defined by WHO as carbohydrate intolerance
Strengths and limitations of this study

- As far as the authors are aware, this study is the first one of its kind in China.

- The data were collected in a specialised hospital for women and children in South China for five consecutive years. It had a large number of annual deliveries and was a regional referral hospital, evidently, the sample was representative.

- The data were collected from the inpatient medical record system of this hospital and the collections were independently verified on a regular basis to avoid the risk of potential bias and loss of records to follow-up.

- The study here is a single-centre retrospective cohort one.

- It is important to be cautious when generalising its findings as a matter of fact twin and multiple births were excluded from this study.

resulting in hyperglycaemia of variable severity with onset or first recognition during pregnancy. ${ }^{1}$ GDM has been worldwide epidemic and its incidence continues to rise. ${ }^{2}$ A worldwide increase of $15 \%-25 \%$ was reported in the past three decades mainly due to a rise in maternal obesity and diabetes. ${ }^{3}$ In particular, the rates of GDM in China increased from $6.0 \%$ in 1994 to $7.8 \%$ in $2005 .{ }^{4}$ The number of older mothers and the cases of obstetric complications have increased since the two-child policy in China, resulting in the increase of gestational diabetes. ${ }^{5}$ A study with 15194 cases from 15 hospitals in Beijing indicated that the GDM incidence was $19.7 \%{ }^{6}$ GDM is associated with maternal age and its incidence is $35.2 \%^{67}$ for women aged $35-39$ years. It is particularly common in women aged $>40$ years. Additionally, a widening of GDM screening criteria, a lowering of 
diagnostic thresholds and an increasing proportion of pregnant women who are classified as overweight or obese ${ }^{89}$ have led to a rise in the incidence of GDM.

GDM leads their exposed off-springs to poor outcomes and its increase in incidence has raised public health concerns. ${ }^{10}$ Macrosomia is a severe complication of infants of mothers with gestational diabetes (IMGD). It may increase the risks of perinatal asphyxia, fracture, cerebral haemorrhage and even death of infants. ${ }^{311}$ An independent correlation exists between abnormal glucose tolerance during pregnancy and the risks of a higher body mass index (BMI) and overweight for children aged 1-6 years. ${ }^{12}$ More studies showed a higher risk of suffering from obesity and metabolic disorders for macrosomia. ${ }^{13}$ The large for gestational age (LGA) infants born to mothers with diabetes tended to be at a high risk of being overweight in adolescence and still at a high lifetime risk of being overweight and suffering form obesity. ${ }^{14}$

Neonatal weight is one of the important indicators in paediatric diagnosis, treatment and care. The curves of neonatal weight are formulated in line with the law of fetal growth. It is not only an indicator of the characteristics of neonatal growth and development but also a clinical approach indispensable for the accurate diagnosis of abnormal birth weight and the quick judgement of the overall nutrition. A large-scale survey of the weight of all the 159334 singleton live births was conducted in 23 provinces, municipalities directly under the central government and autonomous regions in China in 20112014 , based on which a set of reference charts and curves for birth weight were formulated in $2015 .^{15}$ To a certain extent, these charts reflected the real situation of birth weight of all infants at different gestational ages and they have been widely applied by Chinese obstetricians and paediatricians for maternal and neonatal diagnosis, treatment and management. However, data about birth weight standards, specifically for IMGDs and the long-term trends and their continuous observations in China, were very few. In view of this, it was assumed in this study that the mean of birth weight of all IMGDs at the same gestational age was greater than that of all infants at the same gestational age as theirs. The assumption was verified by the data and their analysis. A further purpose of this study was to compare the mean of birth weight of IMGDs with the above-mentioned mean of birth weight in China to provide more reliable reference charts and curves for the diagnosis of suspected abnormal birth weight of IMGDs.

\section{METHODS}

\section{Type of study and participants}

This study was a retrospective cohort one lasting for five consecutive years, enrolling infants born in Fujian Provincial Maternity and Children's Hospital in China from January 2014 to December 2018. This hospital was affiliated to Fujian Medical University. Approximately, 13 000-17 000 babies were delivered here every single year. Thus, the study was on the basis of a single-centre retrospective cohort. GDM diagnostic criteria were from the recommendations from the Obstetrics Group of Chinese Medical Association. ${ }^{16}$ All diagnoses of GDM were confirmed by obstetricians.

The inclusion criteria were: (1) The infants who were exposed to GDM mothers; and (2) who were singleton live births in 2014-2018.

The exclusion criteria were: (1) The infants whose gestational ages were less than 25 weeks or more than 42 weeks; (2) The infants who were with severe congenital malformations or physical defects; (3) Those who were with a fetal edema or a mass in the body in prenatal B-ultrasonic diagnosis; (4) The infants who were with acute blood loss or stillbirths; (5) The infants whose mothers were diagnosed with pregestational diabetes and (6) The infants whose genders were unknown at birth.

Thus, the need for informed consent was waived in the study.

\section{Patients and public involvement}

The data for study were collected from the hospital's inpatient medical record system. The pregnant women were informed that their babies' birth records would be kept for medical and scientific studies.

\section{Definitions and measurements}

The neonatal gestational ages, genders and birth weight were documented as the primary outcomes. At birth, infants were weighed naked by means of calibrated digital scales. The accuracy of the scales was $1 \mathrm{~g}$. The infants' bodies were dried immediately after birth and placed naked on the electronic scale, hence the stable numbers were recorded. The mean of such three body weight (BW) of each infant was recorded as his/her birth weight. Each gestational age was based on the first day of the last normal menstrual period and was confirmed by either the first or the second trimester ultrasonography.

\section{Data collection}

The following maternal data were collected: maternal age at delivery, birth parity, mode of delivery, birth weight and gestational age. Data were collected from the medical record system of the hospital and submitted to the research group regularly. Skilled medical secretaries input such birth records into the database through careful examination on a regular basis. Hence, the completeness of database and accuracy of the data were guaranteed through such procedures. Birth weight was categorised into three outcome variables: low birth weight (LBW, $<2500 \mathrm{~g}$ ), normal birth weight (2500-3999 g) (inclusive) and macrosomia $(\geq 4000 \mathrm{~g})$. In terms of the percentile of the birth weight at the same gestational age, the infants fell into three groups, namely small for gestational age (SGA), appropriate for gestational age (AGA) and large for gestational age (LGA). The criteria for SGA and LGA were respectively defined as an infant whose percentile 


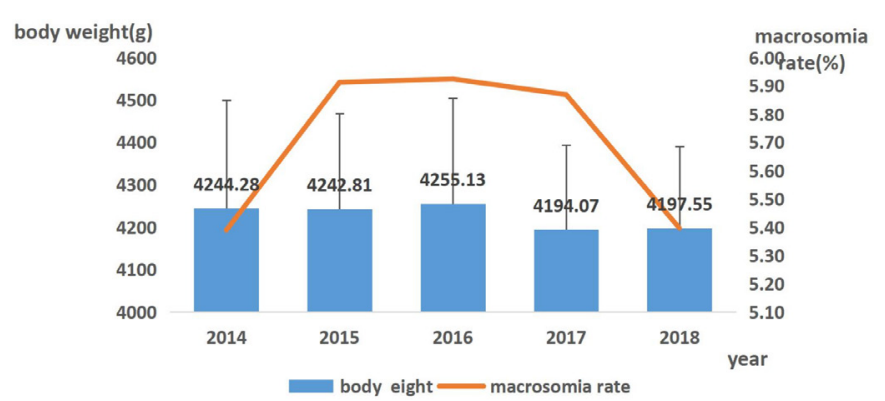

Figure 1 The annual incidence of macrosomia (\%) and the mean of the birth weight in 2014-2018. The $\mathrm{x}$-axis is for year, the primary $y$-axis is for the mean of birth weight $(g)$ and the secondary $y$-axis is the incidence of macrosomia (\%).

of birth weight was $<10 \%$ or $>90 \%$ at the same gestational age. The criterion for AGA was defined as an infant whose percentile of birth weight was between $10 \%$ and $90 \%$ (inclusive).

\section{Data analysis}

Statistical analysis was performed by means of $\mathrm{R}$ for Windows V.3.4.1 and SPSS statistical software (V.25.0, SPSS). The continuous variables were presented as the means and $\mathrm{SD}$, and the categorical variables were presented as numbers (n) and percentages (\%). The continuous variables were analysed by two-unpaired t-test, one sample t-test or one-way analysis of variance for normally distributed data for potential difference(s) in absolute value. LSD was further applied for post hoc test based on one-way analysis of variance, while the categorical variables were analysed by $\chi^{2}$ test for potential difference(s) in proportion. A two-tailed significance test was applied for all comparisons, and statistical significance was defined as $\mathrm{p}<0.05$.

\section{RESULTS}

\section{Characteristics of study population}

A total of 14311 live births of GDM mothers were collected, namely 7805 boys (54.54\%) (7805/14311) and 6506 girls $(45.46 \%)(6506 / 14311)$. The data were complete. The male:female ratio was 1.2:1. The mean of birth weight of all the 14311 infants was $3253.29 \mathrm{~g}$ (SD:543.37).

\section{Weight subgroups}

The proportions of LBW, normal birth weight and macrosomia were, respectively, $7.26 \%$ (1039/14311), $87.04 \%(12457 / 14311)$, and $5.70 \%(815 / 14311)$ in the total population. The incidences of macrosomia in 20142018 consist no statistical difference. They were 5.39\% $(153 / 2839)$ in $2014,5.91 \%(161 / 2723)$ in $2015,5.92 \%$ $(150 / 2532)$ in 2016, $5.87 \%(205 / 3493)$ in 2017 and $5.40 \%(147 / 2724)$ in 2018 (for boys, $\chi^{2}=9.962, \mathrm{p}=0.268$; and for girls, $\left.\chi^{2}=3.802, \mathrm{p}=0.874\right)$.

\section{Means of weight in subgroups}

The neonatal means for LBW, normal birth weight and macrosomia were 1969.98 (SD:453.53), 3296.68 (SD:342.81) and 4224.95 (SD:225.16) g, respectively. In the macrosomia group, the mean of neonatal weight decreased from the highest of $4244.28 \mathrm{~g}$ in 2014 to the lowest of $4194.07 \mathrm{~g}$ in 2017. Statistical difference was derived from the mean of birth weight in the macrosomia group $(\mathrm{F}=2.740, \mathrm{p}=0.028$, figure 1). Further LSD post hoc tests indicated a decrease of the mean of birth weight since 2017. From 2016 to 2017, $\mathrm{p}=0.011,95 \%$ CI 13.77 to 108.34 .

\section{SGA and LGA}

The proportions of SGA, AGA and LGA were $5.69 \%$ $(814 / 14311), \quad 84.42 \% \quad(12082 / 14311), \quad$ and $9.89 \%$ (1415/14311), respectively. No statistical difference was derived from the ratios of SGA and LGA from 2014 to 2018 (for boys, $\chi^{2}=14.540, p=0.069$; and for girls, $\chi^{2}=6.313$, $\mathrm{p}=0.612$ ).

\section{Mean of birth weight of IMGDs of each gestational age}

Nearly all such percentiles of birth weight at all gestational ages as 3rd, 10th, 25h, 50th, 75th, 90th and 97th were identified in table 1 . With the increase in gestational age, the mean of birth weight with the same percentile increased accordingly. The distribution of percentiles of weight at different gestational ages are presented in table 1 and the corresponding curves for such weight were shown in figure 2.

\section{Comparison between the means of birth weight of IMGDs at different gestational ages and those of all infants at the same gestational ages in China}

Based on the comparison between the means of birth weight of IMGDs at different gestational ages and those of all infants at the same gestational ages in China, ${ }^{14}$ it was revealed that boys at the gestational ages of 36-41 weeks and girls at 38-41 weeks both weighed more than this mean, which was shown in table 2.

\section{Comparison between the means of birth weight of IMGDs at the gestational ages of each two neighbouring weeks}

The increase of the mean of birth weight of the infants of each gestational age over that of its former gestational age was calculated to identify the trend of the means of weight of the infants at different gestational ages with the further purpose of identifying the key periods for the prenatal weight management of the women with diabetes. Statistical sense was derived from the weekly increase in weeks 27-40. It was noted that the weekly increase in weeks 27-31 and 33-35 was more than 10\% ( $<<0.05$, table 3$)$.

\section{DISCUSSION}

In the data collected, the proportions of LBW, normal birth weight and macrosomia were $7.26 \%$ (1039/14311), $87.04 \%(12457 / 14311)$ and $5.70 \%(815 / 14311)$, respectively. The proportions of the small, the appropriate and the LGA were $5.69 \%$ (814/14311), 84.42\% (12082/14311) and 9.89\% (1415/14311), respectively. In the macrosomia group, the mean of neonatal weight decreased from the highest of $4244.28 \mathrm{~g}$ in 2014 to the 


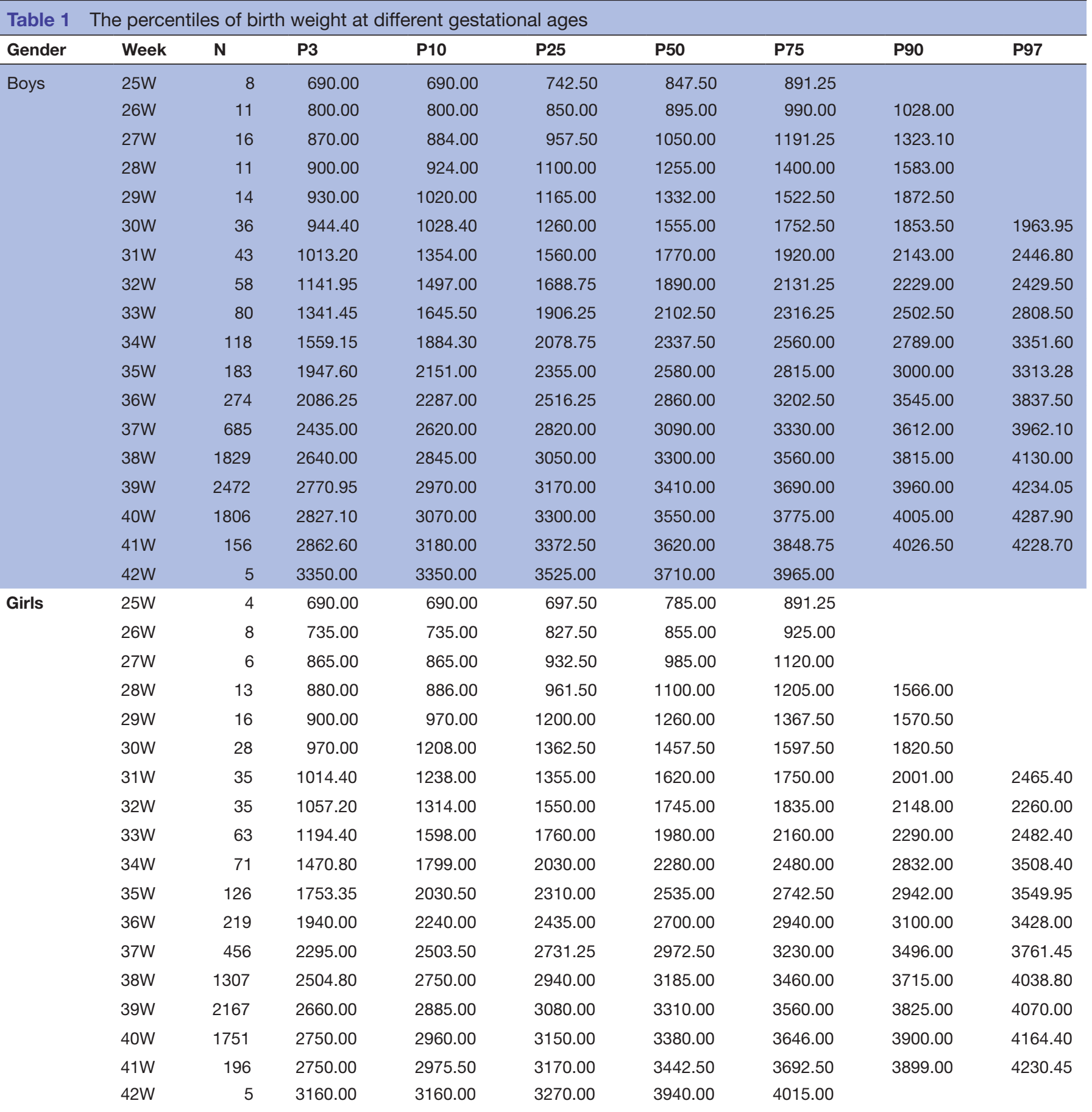

lowest of $4194.07 \mathrm{~g}$ in 2017. Through the comparison with the mean of birth weight of all infants in China, ${ }^{15}$ it is clear that boys born to mothers with GDM at the gestational ages of 36-41 weeks and girls at 38-41 weeks both weighed more than this mean. All the increases of the means of birth weight of all IMGDs in the gestational weeks 27-40 derived statistical difference, and all the means of birth weight in the gestational weeks 27-31 and 33-35 were more than $10 \%$ greater. The data here enable development of new weight curves.

Birth weight is considered when postnatal nutrition, recovery from some disease(s) and growth are evaluated.
The immediate identification of abnormal birth weight is of key significance for later treatment. The application of different reference charts and curves of birth weight may result in different identifications of macrosomia and LGA, thus playing a significant role in clinical practice and scientific research. As a matter of fact, customised reference charts of weight including some demographic and clinical variables that might affect BW of particular groups of people were formulated and have been widely applied. ${ }^{1718}$ Another study in the USA presented its findings from a database relating to 118 cases of women who were with pre-eclampsia and delivered at the gestational ages of 23-41 weeks. And 

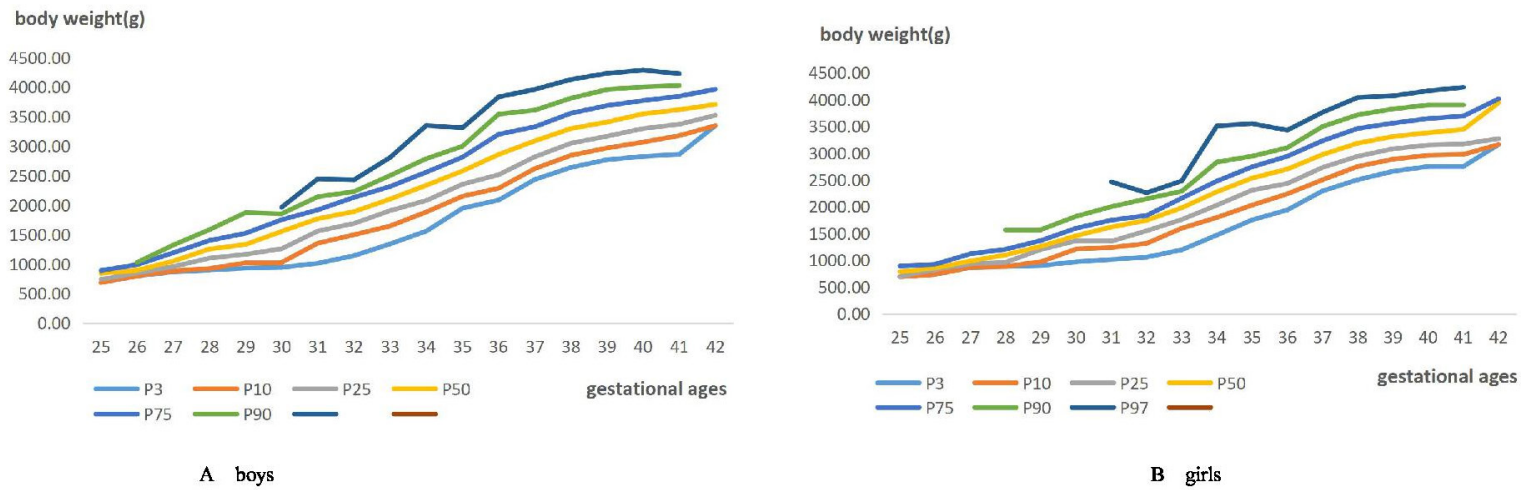

Figure 2 Trends of the percentiles of birth weight of infants of mothers with diabetes at different gestational ages in South China from 2014 to 2018. The $x$-axis is for gestational age, and the $y$-axis is for the birth weight (g). The curves of the percentiles of 3th, 10th, 25th, 50th, 75th, 90th and 97th are drawn, respectively. A is for boys,and B is for girls.

based on a comparison between the different proportions of LGA of the infants in terms of the new customised growth curves and the national birth weight chart, it was indicated that the application of the new customised reference charts led to a significant difference in the identified frequency of LGA infants of women who were with pre-eclampsia and delivered at the gestational ages of more than 34 weeks. ${ }^{19}$ In view of that, this study is highly practical. It is suggested that this new customised criteria be applied for the diagnosis of abnormal birth weight of IMGDs and for clinical practice and scientific studies. Further multicentre studies aiming at the birth weight of IMGDs are suggested in the future for the purpose of providing more accurate reference for the evaluation of growth and nutrition in early infancy and assisting doctors in paediatric diagnosis and treatment.

Macrosomia and/or LGA is one the major adverse outcomes associated with maternal hyperglycaemia. ${ }^{20}$ As a matter of fact that prenatal exposure to GDM has been linked to higher risk of LGA and fetal macrosomia. ${ }^{21}$ In the context of hyperglycaemia during the pregnancy, IMGDs have significantly greater risk of adiposity than those born to mothers with normal glucose tolerance. ${ }^{22}$ Another study indicated that macrosomia among IMGDs were heavier than those born to normal pregnant women. ${ }^{23}$

The incidence of macrosomia among IMGDs is approximately $10 \%-30 \%$ worldwide. ${ }^{24}$ One study indicated that

Table 2 Comparison between the means of birth weight of IMGDs at different gestational ages and those of all infants at the same gestational ages in China

\begin{tabular}{|c|c|c|c|c|c|c|c|c|}
\hline \multicolumn{5}{|l|}{ Boys } & \multicolumn{4}{|l|}{ Girls } \\
\hline Week & P50 & P50 of 2015 & $P$ value & $95 \% \mathrm{Cl}$ & P50 & P50 of 2015 & $P$ value & $95 \% \mathrm{Cl}$ \\
\hline $25 \mathrm{~W}$ & 847.50 & 766 & 0.114 & -24.95 to 185.45 & 785.00 & 662 & 0.087 & -34.37 to 292.87 \\
\hline $27 \mathrm{~W}$ & 1050.00 & 1053 & 0.470 & -50.35 to 104.10 & 985.00 & 960 & 0.310 & -61.67 to 158.33 \\
\hline $28 \mathrm{~W}$ & 1255.00 & 1196 & 0.324 & -73.96 to 202.87 & 1100.00 & 1109 & 0.815 & -119.40 to 148.78 \\
\hline $31 \mathrm{~W}$ & 1770.00 & 1666 & 0.140 & -24.08 to 164.64 & 1620.00 & 1591 & 0.736 & -85.32 to 119.60 \\
\hline $32 \mathrm{~W}$ & 1890.00 & 1857 & 0.597 & -61.75 to 106.37 & 1745.00 & 1782 & 0.246 & -155.53 to 41.24 \\
\hline $33 \mathrm{~W}$ & 2102.50 & 2071 & 0.340 & -46.34 to 132.54 & 1980.00 & 1993 & 0.292 & -121.90 to 37.30 \\
\hline $34 \mathrm{~W}$ & 2337.50 & 2306 & 0.389 & -41.49 to 105.88 & 2280.00 & 2225 & 0.159 & -29.22 to 174.85 \\
\hline $38 \mathrm{~W}$ & 3300.00 & 3273 & 0.000 & 29.97 to 66.81 & 3185.00 & 3153 & 0.000 & 40.26 to 83.41 \\
\hline $39 \mathrm{~W}$ & 3410.00 & 3399 & 0.000 & 28.26 to 59.17 & 3310.00 & 3275 & 0.000 & 39.94 to 70.95 \\
\hline $40 \mathrm{~W}$ & 3550.00 & 3482 & 0.000 & 45.81 to 80.98 & 3380.00 & 3349 & 0.000 & 114.09 to 149.28 \\
\hline $41 \mathrm{~W}$ & 3620.00 & 3545 & 0.038 & 3.50 to 118.56 & 3442.50 & 3402 & 0.096 & -8.01 to 97.84 \\
\hline $42 \mathrm{~W}$ & 3710.00 & 3602 & 0.304 & -184.84 to 456.84 & 3940.00 & 3448 & 0.232 & -247.48 to 755.48 \\
\hline
\end{tabular}

IMGDs, infants of mothers with gestational diabetes. 
Table 3 Test for independent samples of the difference of means of birth weight in each two neighbouring gestational ages

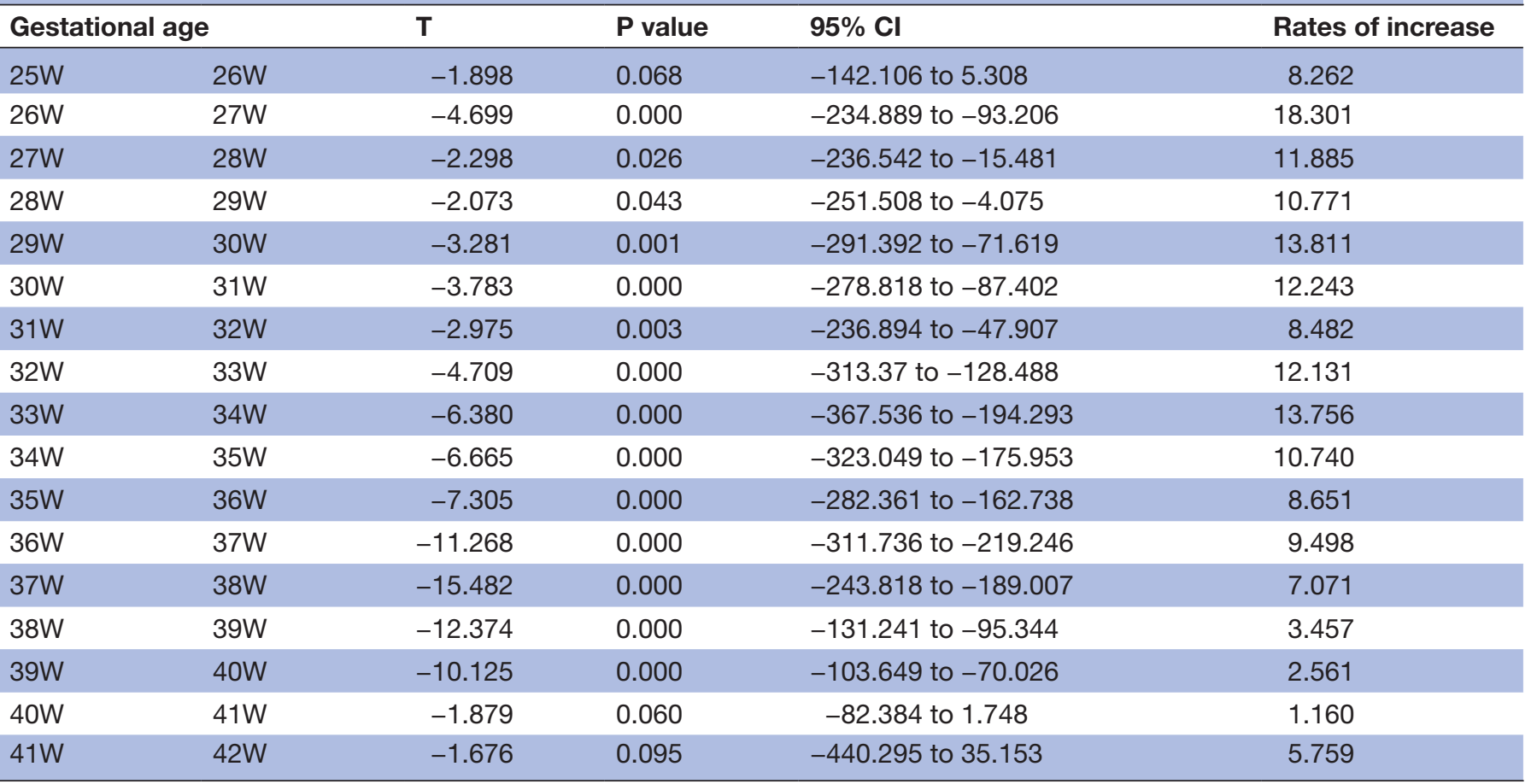

the incidences of macrosomia among women with and without GDM were $6.8 \%$ and $5.0 \% .^{20}$ The incidence of macrosomia in infants born to GDM mothers in Iran was $8.7 \% .^{25}$ A previous meta-analysis of 110968 infants showed that the probability of neonatal LGA in the GDM group was 2.12 times of that in the pregnance group with normal blood glucose, The OR was 2.12 (95\% CI 1.97 to 2.29$).{ }^{26}$ A population-based cohort study in Sweden showed that the probability of neonatal LGA in the GDM group was 3.43 (95\% CI 3.21 to 3.67$)$ times of that in the non-GDM group, ${ }^{27}$ a remarkable higher risk proportion. Undoubtedly, it is necessary to strengthen the management of gestational diabetes.

To what extent could screening for and treatment of GDM improve maternal and fetal outcomes is a question that obstetricians and paediatricians need to consider. The keys to the management of GDM are optimisation of lifestyle, self-monitoring of blood glucose, intensification of patients' education and introduction of medication when necessary. ${ }^{28}$ Improvement of the prenatal diagnosis, management of dysglycaemia and treatment of GDM were supposed to decrease the risk of fetal macrosomia. ${ }^{29}$ Recognising and treating GDM and strengthening glycaemic control were confirmed to have reduced obstetric and paediatric complications in randomised controlled trials. ${ }^{28}$ Additionally, dietary treatment of GDM was found to decrease such risk of pregnancy complications as excessive fetal growth without increasing the incidence of SGA. ${ }^{30}$ Principles for such dietary treatment involve meeting normal nutritional requirements for the pregnant, managing gestational weight gain, dropping carbohydrates with high glycaemic index and ensuring an adequate intake of carbohydrates with low glycaemic index. ${ }^{31}$ Moderate exercise on a regular basis was helpful in maintaining glycaemic levels within target.

It was found in this study that after a gestational age of 36 weeks the mean of the birth weight of IMGDs was greater than that of all infants in China. In this study hospital, a total of $5.70 \%(815 / 14311)$ of IMGDs were macrosomia, $5.69 \%(814 / 14311)$ were SGA and $9.90 \%$ (1415/14311) were LGA. The respective incidence of macrosomia, SGA and LGA in China was lower than that reported in other countries. And also in this hospital, the mean of the birth weight of macrosomia in 2017 began to decrease since 2014, indicating that management of pregnant women with GDM in outpatient clinics has achieved initial success. It was our experience to establish GDM specialised outpatient clinic to provide such service and to develop standardised management of clinical pathways. Women here received one-on-one education/counselling and an individualised GDM plan of care designed by a professional doctor or nurse. These included information on blood glucose testing, diet for women with diabetes, exercise and self-care activities. Measuring blood glucose four times per day was required, namely before breakfast and 1-2 hours after three meals. Health education activities for GDM were carried out, and awareness among pregnant women was promoted through lectures, salons and brochures. Urgent referral is necessary for overt diabetes.

Studies in other provinces in China have shown that among the risk factors of macrosomia, the OR of pregnant women's BMI was $1.14(1.10-1.19)$ and the OR of their blood glucose was 1.11 (1.01-1.23). Therefore, a high BMI measured in GDM screening was the most important determinant of the risk of macrosomia. ${ }^{32}$ In a 
Cuban study, such maternal conditions as overweight or obesity before pregnancy, excessive weight gain during the pregnancy, inadequate glycaemic control and hypertriglyceridemia were identified as risk factors for IMGD macrosomia. ${ }^{33}$ The key periods of weeks $27-31$ and $33-35$ for fetal weight gain identified in table 3 in this study may be applied as reference for the management of weight during the pregnancy in obstetrics. For example, during these 8 weeks, obstetricians may be encouraged to counsel women with GDM especially those with a high BMI and to strengthen the management of their weight, and relevant hospitals may be suggested to set up specialised consultation clinics to provide individualised diet and exercise prescriptions, monitor blood glucose more closely and encourage them to control their weight within an acceptable range. By early intervention, they can avoid macrosomia-the major complication for IMGD.

\section{Limitations of this study}

Some limitations to this study should be acknowledged. It was an observational study and conducted among pregnant women in a specialist centre, which might limit the extrapolation of the results and make the findings different from an unbiased sample of Chinese IMGDs in terms of the distribution of percentiles of birth weight. Twin and multiple births were excluded here. Therefore, this study was not representative of all the Chinese infants born to mothers diagnosed with diabetes. More studies in multiple institutions in different regions are suggested to confirm such results.

\section{CONCLUSION}

Excessive birth weight for IMGDs will continue to be a major issue of public health. The mean of birth weight of IMGDs was greater than that of all infants in China. Use of these charts and curves may result in more accurate recognition of abnormal fetal growth and risk in IMGDs. Further studies are suggested to evaluate the risk for adverse neonatal and long-term outcomes among IMGDs. More multicentre and prospective studies aiming at controlling and preventing risk factors for macrosomia and LGA and detrimental outcomes in mothers and perinatal children are also suggested.

\section{Twitter Xin-xin Huang @huangxx}

Contributors X-MJ: study design, quality control, supervision, writing-review and editing; $\mathrm{XH}$ : conception and design, data collection and analysis, quality control, manuscript drafting and revision; $Q-X Z$ : data collection and interpretation, manuscript drafting; $\mathrm{X}-\mathrm{QC}$ : data analysis and interpretation; $\mathrm{Y}-\mathrm{QP}$ : data analysis and interpretation.

Funding The authors have not declared a specific grant for this research from any funding agency in the public, commercial or not-for-profit sectors.

Competing interests None declared.

Patient and public involvement Patients and/or the public were not involved in the design, or conduct, or reporting, or dissemination plans of this research.

Patient consent for publication Not required.

Ethics approval This study was approved by the Human Subjects Committee of Fujian Maternity and Child Health Hospital and all the methods were performed in compliance with the relevant guidelines and regulations. The patients' records and information were anonymised and deidentified before analysis.

Provenance and peer review Not commissioned; externally peer reviewed.

Data availability statement Data are available on reasonable request. Data may be obtained from a third party and are not publicly available. The authors are not authorised to share non-aggregated data with a third party. However, data are available from the corresponding author on reasonable request. Online supplemental material in this content has been supplied by the authors. It has not been vetted by BMJ Publishing Group and may not have been peer-reviewed.

Open access This is an open access article distributed in accordance with the Creative Commons Attribution Non Commercial (CC BY-NC 4.0) license, which permits others to distribute, remix, adapt, build upon this work non-commercially, and license their derivative works on different terms, provided the original work is properly cited, appropriate credit is given, any changes made indicated, and the use is non-commercial. See: http://creativecommons.org/licenses/by-nc/4.0/.

ORCID iD

Xin-xin Huang http://orcid.org/0000-0002-3611-3061

\section{REFERENCES}

1 World Health Organization and Department of Noncommunicable Disease Surveillance. Definition, diagnosis and classification of diabetes mellitus and its complications. Report of a who consultation. Part 1: diagnosis and classification of diabetes mellitus. Geneva: World Health Organization, 1999.

2 Anna V, van der Ploeg HP, Cheung NW, et al. Sociodemographic correlates of the increasing trend in prevalence of gestational diabetes mellitus in a large population of women between 1995 and 2005. Diabetes Care 2008;31:2288-93.

3 Henriksen T. The macrosomic fetus: a challenge in current obstetrics. Acta Obstet Gynecol Scand 2008;87:134-45.

4 Lu Y, Zhang J, Lu X, et al. Secular trends of macrosomia in Southeast China, 1994-2005. BMC Public Health 2011;11:818.

5 Noctor E, Dunne FP. Type 2 diabetes after gestational diabetes: the influence of changing diagnostic criteria. World J Diabetes 2015;6:234e44.

6 Zhu W-W, Yang H-X, Wang C, et al. High prevalence of gestational diabetes mellitus in Beijing: effect of maternal birth weight and other risk factors. Chin Med J 2017;130:1019-25.

7 Karcaaltincaba D, Calis P, Ocal N, et al. Prevalence of gestational diabetes mellitus evaluated by universal screening with a 75-g, 2hour oral glucose tolerance test and IADPSG criteria. Int J Gynaecol Obstet 2017;138:148-51.

8 Diabetes in pregnancy. Management of diabetes and its complications from preconception to the postnatal period. London, UK: National Institute of Clinical Excellence, 2008. http://www.nice. org.uk/CG63

9 International Association of Diabetes and Pregnancy Study Groups Consensus Panel, Metzger BE, Gabbe SG, et al. International association of diabetes and pregnancy study groups recommendations on the diagnosis and classification of hyperglycemia in pregnancy. Diabetes Care 2010;33:676-82.

10 Zhang H-X, Zhao Y-Y, Wang Y-Q. Analysis of the characteristics of pregnancy and delivery before and after implementation of the Twochild policy. Chin Med J 2018;131:37-42.

11 Koyanagi A, Zhang J, Dagvadorj A, et al. Macrosomia in 23 developing countries: an analysis of a multicountry, facility-based, cross-sectional survey. Lancet 2013;381:476-83.

12 Wang J, Pan L, Liu E, et al. Gestational diabetes and offspring's growth from birth to 6 years old. Int J Obes 2019;43:663-72.

13 Boney CM, Verma A, Tucker R, et al. Metabolic syndrome in childhood: association with birth weight, maternal obesity, and gestational diabetes mellitus. Pediatrics 2005;115:e290-6.

14 Hammoud NM, Visser GHA, van Rossem L, et al. Long-Term BMI and growth profiles in offspring of women with gestational diabetes. Diabetologia 2018;61:1037-45.

15 Zhu L, Zhang R, Zhang S, et al. [Chinese neonatal birth weight curve for different gestational age]. Zhonghua Er Ke Za Zhi 2015;53:97-102.

16 Kc K, Shakya S, Zhang H. Gestational diabetes mellitus and macrosomia: a literature review. Ann Nutr Metab 2015;66 Suppl 2:14e20:14-20.

17 Odibo AO, Cahill AG, Odibo L, et al. Prediction of intrauterine fetal death in small-for-gestational-age fetuses: impact of including 
ultrasound biometry in customized models. Ultrasound Obstet Gynecol 2012;39:288-92.

18 Law TL, Katikaneni LD, Taylor SN, et al. Customized versus population-based growth curves: prediction of low body fat percent at term corrected gestational age following preterm birth. J Matern Fetal Neonatal Med 2012;25:1142-7.

19 Espinoza J, Lee W, Martin SR, et al. Customized growth curves for identification of large-for-gestational age neonates in pre-eclamptic women. Ultrasound Obstet Gynecol 2014;43:165-9.

20 Soliman A, Salama H, Al Rifai H, et al. The effect of different forms of dysglycemia during pregnancy on maternal and fetal outcomes in treated women and comparison with large cohort studies. Acta Biomed 2018;89:11-21.

21 Longmore DK, Barr ELM, Lee I-L, et al. Maternal body mass index, excess gestational weight gain, and diabetes are positively associated with neonatal adiposity in the pregnancy and neonatal diabetes outcomes in remote Australia (Pandora) study. Pediatr Obes 2019;14:e12490.

22 Metzger BE, HAPO Study Cooperative Research Group. Hyperglycemia and adverse pregnancy outcome (HAPO) study: associations with neonatal anthropometrics. Diabetes 2009;58:453-9.

23 Rao J, Fan D, Wu S, et al. Trend and risk factors of low birth weight and macrosomia in South China, 2005-2017: a retrospective observational study. Sci Rep 2018;8:3393.

24 Moses RG, Morris GJ, Petocz P, et al. The impact of potential new diagnostic criteria on the prevalence of gestational diabetes mellitus in Australia. Med J Aust 2011;194:338-40.
25 Nouhjah S, Shahbazian H, Latifi SM, et al. Body mass index growth trajectories from birth through 24 months in Iranian infants of mothers with gestational diabetes mellitus. Diabetes Metab Syndr 2019:13:408-12.

26 Shen Hao LH. Meta-analysis of gestational diabetes mellitus and neonatal weight. Traffic Med 2018;32:293-7.

27 Fadl HE, Östlund IKM, Magnuson AFK, et al. Maternal and neonatal outcomes and time trends of gestational diabetes mellitus in Sweden from 1991 to 2003. Diabet Med 2010;27:436-41.

28 Landon MB, Spong CY, Thom E, et al. A multicenter, randomized trial of treatment for mild gestational diabetes. $N$ Engl J Med 2009;361:1339-48.

29 Shen S, Lu J, Zhang L. Single fasting plasma glucose versus $75-\mathrm{g}$ oral glucose tolerance test in prediction of adverse perinatal out comes: a cohort study. EBio Medicine 2017;16:284-91.

30 Kgosidialwa O, Egan AM, Carmody L, et al. Treatment with diet and exercise for women with gestational diabetes mellitus diagnosed using IADPSG criteria. J Clin Endocrinol Metab 2015;100:4629-36.

31 Lee-Parritz A. Contemporary management of gestational diabetes. Curr Opin Endocrinol Diabetes Obes 2011;18:395-400.

32 Liu J, Leng J, Tang C, et al. Maternal glucose level and body mass index measured at gestational diabetes mellitus screening and the risk of macrosomia: results from a perinatal cohort study. BMJ Open 2014;4:e004538.

33 Cruz J, Grandía R, Padilla L, et al. Macrosomia predictors in infants born to Cuban mothers with gestational diabetes. MEDICC Rev 2015;17:27-32. 